\title{
Origin of the high specific capacity in sodium manganese hexacyanomanganate
}

\author{
Kevin Hurlbutt, ${ }^{\dagger}$ Feliciano Giustino, ${ }^{\ddagger}, \llbracket$ George Volonakis, ${ }^{*}$, and Mauro Pasta*,† \\ $\dagger$ Department of Materials, University of Oxford, Parks Road, Oxford OX1 3PH, United \\ Kingdom \\ $\ddagger$ Oden Institute for Computational Engineering and Sciences, The University of Texas at \\ Austin, Austin, Texas 78712, United States \\ \Department of Physics, The University of Texas at Austin, Austin, Texas 78712, United \\ States \\ $\S U n i v$ Rennes, ENSCR, INSA Rennes, CNRS, ISCR (Institut des Sciences Chimiques de \\ Rennes), UMR 6226, Rennes, France
}

E-mail: yorgos.volonakis@univ-rennes1.fr; mauro.pasta@materials.ox.ac.uk

\begin{abstract}
Sodium manganese hexacyanomanganate, $\mathrm{Na}_{\mathrm{x}} \mathrm{Mn}\left[\mathrm{Mn}(\mathrm{CN})_{6}\right]$, is an electrochemically active Prussian blue analog (PBA) that has been studied experimentally as an electrode material in rechargeable sodium-ion batteries. It has a reversible specific capacity of $209 \mathrm{~mA} \mathrm{~h} \mathrm{~g}^{-1}$, which is substantially higher than the theoretical specific capacity of $172 \mathrm{~mA} \mathrm{~h} \mathrm{~g}^{-1}$ expected for two reduction events conventional in the PBAs. It has been suggested the high specific capacity originates from this compound's unique ability to insert a third sodium ion per formula unit. However, the plausibility of this mechanism has remained ambiguous. Here we use density-functional theory (DFT) with a hybrid functional to calculate the formation energies of various oxidation states
\end{abstract}


and magnetic phases of the $\mathrm{Na}_{\mathrm{x}} \mathrm{Mn}\left[\mathrm{Mn}(\mathrm{CN})_{6}\right]$ system. We confirm that the compound $\mathrm{Na}_{3} \mathrm{Mn}^{\mathrm{II}}\left[\mathrm{Mn}^{\mathrm{I}}(\mathrm{CN})_{6}\right]$ is, indeed, thermodynamically stable. It contains manganese(I) and the sodium ions occupy the interfacial position of the lattice subcubes. We also provide strong evidence that the phase of the fully oxidized $\mathrm{Mn}\left[\mathrm{Mn}(\mathrm{CN})_{6}\right]$ compound is charge-disproportionated, containing manganese(II) and manganese(IV). We proceed to show that the presence of crystalline water increases the reduction potential of the system and that the hydrated compounds have theoretical crystal geometries and reduction potentials that closely match experiment. This work clarifies the chargestorage mechanism in a well-known but less-understood PBA.

\section{Introduction}

The Prussian blue analogs (PBAs) are a family of electrochemically active compounds with great promise as electrode materials in next-generation batteries. ${ }^{1,2}$ They have a wide composition space, and they are capable of reversible electrochemical reaction with diverse metals including sodium, ${ }^{3}$ potassium,${ }^{4}$ rubidium,${ }^{5}$ magnesium,${ }^{6}$ aluminum, ${ }^{7}$ and others. Depending on their composition, PBAs can insert one or two ions into the interstitial subcube of their open-framework crystal structure. ${ }^{8}$ In addition to their technological relevance, PBAs are a useful platform for the study of phenomena in solid-state physics and inorganic chemistry, including charge-transfer-accompanied spin transitions ${ }^{9}$ and mixed valency. ${ }^{10}$

Sodium manganese hexacyanomanganate, $\mathrm{Na}_{\mathrm{x}} \mathrm{Mn}\left[\mathrm{Mn}(\mathrm{CN})_{6}\right]$, is a PBA of particular interest. In 2014 Pasta and coworkers ${ }^{11}$ observed a reversible specific capacity in sodium manganese hexacyanomanganate of $209 \mathrm{~mA} \mathrm{~h} \mathrm{~g}^{-1}$. This is $22 \%$ higher than the theoretical specific capacity that would be expected from the reversible (de)insertion of two sodium ions per formula unit. Furthermore, they observed three distinct voltage plateaus in the galvanostatic discharge profile. It was hypothesized that the extra capacity came from the insertion of a third sodium ion with the reduction of the carbon-coordinated manganese to manganese(I), as shown in Figure 1. The study included high-quality synchrotron X-ray 
diffraction $(\mathrm{XRD})$ data, but the authors were unable to refine the structure sufficiently to determine conclusively the positions or number of the sodium ions. Work from Wessells and coworkers in $2018^{12}$ provided good X-ray spectroscopic evidence for the formation of monovalent manganese, supporting the idea that the material inserts three sodium ions.

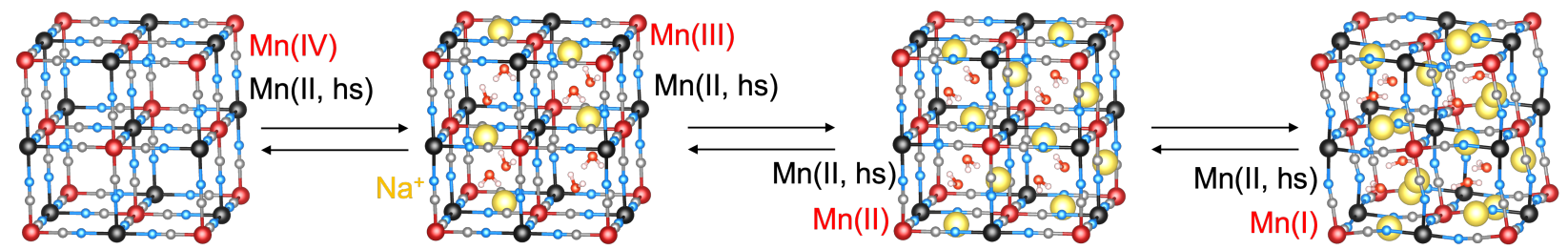

Figure 1: Schematic of the reversible insertion of three sodium ions (per formula unit) into the open-framework $\mathrm{Mn}\left[\mathrm{Mn}(\mathrm{CN})_{6}\right]$. Darker red atoms are carbon-coordinated manganese, black atoms are nitrogen-coordinated manganese, gray are carbon, light blue are nitrogen, gold are sodium, lighter red are oxygen, and white are hydrogen.

Here we investigate the material theoretically using density-functional theory (DFT) using a hybrid functional to account for the strong electronic correlation in this material. ${ }^{13}$ First, we calculate the formation energies of a pseudo-binary mixture of sodium atoms with manganese hexacyanomanganate (empty of any interstitial sodium atoms) to build the convex hull and to determine whether the hypothetical compound $\mathrm{Na}_{3} \mathrm{Mn}\left[\mathrm{Mn}(\mathrm{CN})_{6}\right]$ is thermodynamically stable. We discuss the crystal structure of the simulated compounds compared to the experiment. We then examine the compounds' electronic structure and oxidation states through their projected densities of states. Finally, we investigate the effect the crystalline water has on the stability of the system. We construct the phase diagram of the ground state composition $\mathrm{Na}_{\mathrm{x}} \mathrm{Mn}\left[\mathrm{Mn}(\mathrm{CN})_{6}\right] \cdot \mathrm{wH}_{2} \mathrm{O}$ by calculating the system's grand potential. We use this to discuss the effect of crystalline water on the material's reduction potential versus $\mathrm{Na}^{+} / \mathrm{Na}$. This work is the first thorough, theoretical investigation of one of the most important PBA compositions ever reported, because it has the highest-ever reversible specific capacity for sodium ions. We present data on the material's crystal structure and electronic structure that are in excellent agreement with experimental data and that, together, answer conclusively the question of the origin of the high specific capacity in 
sodium manganese hexacyanomanganate.

\section{Results and discussion}

\section{Convex hull of formation energies}

The formation energy of a pseudo-binary mixture of sodium atoms with the empty manganese hexacyanomanganate lattice (that is, the lattice containing no inserted sodium atoms) is

$$
E_{f}(x)=\frac{E\left(\mathrm{Na}_{\mathrm{x}} \mathrm{Mn}\left[\mathrm{Mn}(\mathrm{CN})_{6}\right]\right)-E\left(\mathrm{Mn}\left[\mathrm{Mn}(\mathrm{CN})_{6}\right]\right)-x E(\mathrm{Na})}{1+x}
$$

in which $x$ is the number of sodium atoms per formula unit. ${ }^{14,15}$ The total energy also depends strongly on the unit cell's magnetic moment. For each value of $x$, various electronic configurations are plausible depending on the manganese ions' oxidation states, spin configurations (that is low spin versus high spin), and spin alignment. The formation energies for the phases including the different magnetic configurations are shown in Figure 2.

For the fully oxidized compound, $\mathrm{Mn}\left[\mathrm{Mn}(\mathrm{CN})_{6}\right]$, the two magnetic phases, $6 \mu_{\mathrm{B}}$ and $8 \mu_{\mathrm{B}}$, where $\mu_{\mathrm{B}}$ is the Bohr magneton, are essentially degenerate. As discussed in the next section, the two phases have very different crystal structures, and only the $8 \mu_{\mathrm{B}}$ phase is in excellent agreement with experiment. For the compound $\mathrm{NaMn}\left[\mathrm{Mn}(\mathrm{CN})_{6}\right]$, the ground-state magnetization is $7 \mu_{\mathrm{B}}$ and is well separated in energy from the other magnetic phases. The compound $\mathrm{Na}_{2} \mathrm{Mn}\left[\mathrm{Mn}(\mathrm{CN})_{6}\right]$ has a ground-state magnetization of $6 \mu_{\mathrm{B}}$. The ground-state magnetization for the compound $\mathrm{Na}_{3} \mathrm{Mn}\left[\mathrm{Mn}(\mathrm{CN})_{6}\right]$ is $5 \mu_{\mathrm{B}}$. For $\mathrm{Na}_{4} \mathrm{Mn}\left[\mathrm{Mn}(\mathrm{CN})_{6}\right]$, the two magnetic phases $\mu=6 \mu_{\mathrm{B}}$ and $\mu=4 \mu_{\mathrm{B}}$ are degenerate.

The sodium ions reside in the faces separating two subcubes. (The subcube vertices are 8 manganese ions and the edges are cyanide ligands.) For the compound $\mathrm{Na}_{2} \mathrm{Mn}\left[\mathrm{Mn}(\mathrm{CN})_{6}\right]$ there are two arrangements of the sodium ions which are local minima on the potential energy surface. In one arrangement, the sodium ions occupy faces that share an edge, referred to in 


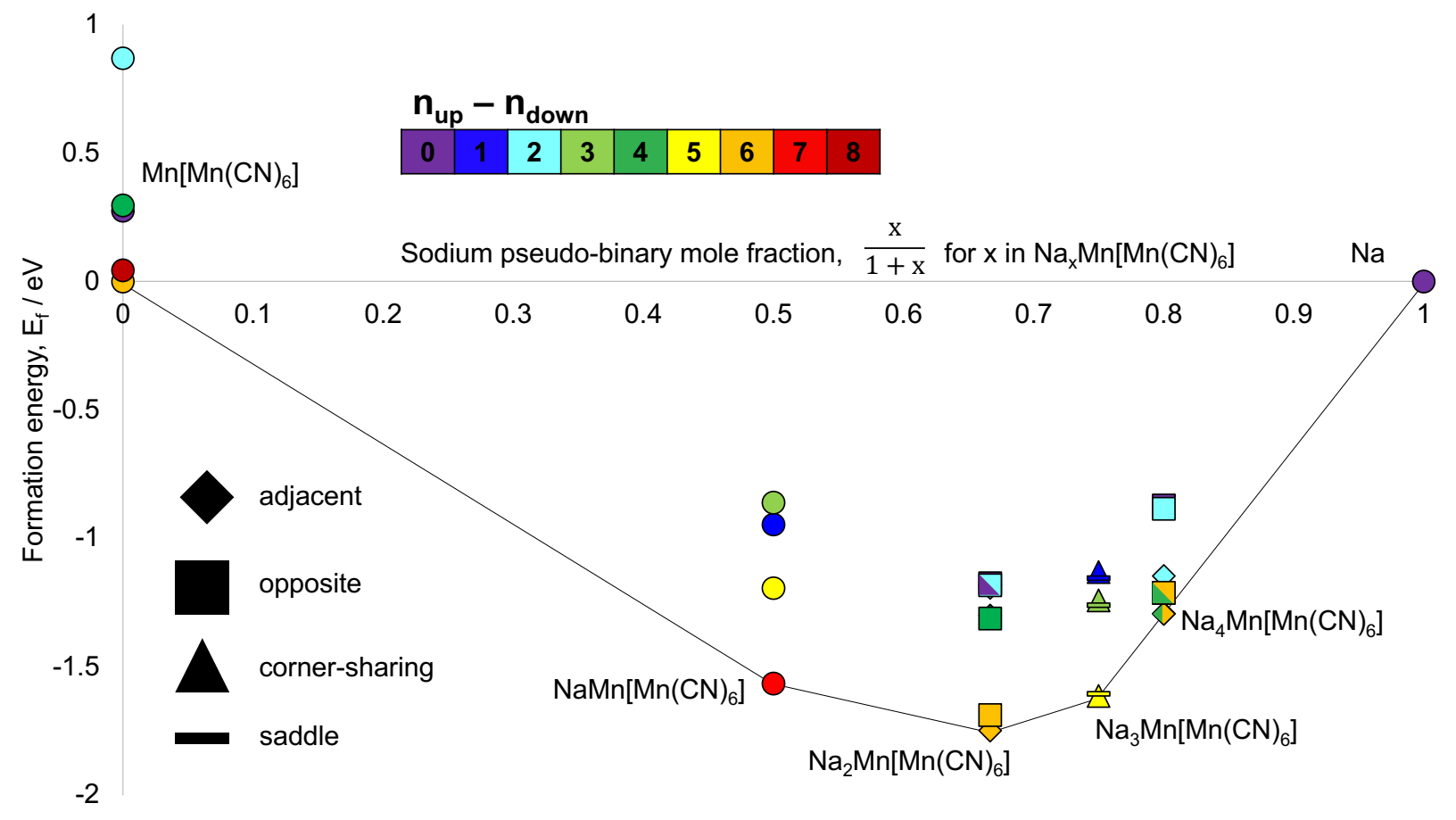

Figure 2: Formation energies for the $\mathrm{Na}_{\mathrm{x}} \mathrm{Mn}\left[\mathrm{Mn}(\mathrm{CN})_{6}\right]$ system. The color of the data points signifies the total magnetic moment of the unit cell (in units of the Bohr magneton), which is equal to the difference between the number of majority- and minority-spin electrons. The shapes of the data points are at the left. The convex hull is connected by the black line. 
Figure 2 as "adjacent". (See Figure SI.1.) In the other arrangement, the sodium ions occupy subcube faces opposite each other, referred to here as "opposite". The edge-sharing phase is just $11 \mathrm{meV}$ atom $^{-1}$ lower in energy. For $\mathrm{Na}_{3} \mathrm{Mn}\left[\mathrm{Mn}(\mathrm{CN})_{6}\right]$, there are also two possible sodium-ion arrangements. The three ions can occupy either three faces of the interstitial subcube that share a corner or three faces in a "saddle" arrangement. These two phases are essentially degenerate in energy (the corner-sharing arrangement is $2 \mathrm{meV}$ atom $^{-1}$ lower in energy). In the two sodium-ion arrangements for $\mathrm{Na}_{4} \mathrm{Mn}\left[\mathrm{Mn}(\mathrm{CN})_{6}\right]$, the faces that do not contain a sodium ion are either edge-sharing or opposite. The adjacent arrangement is the ground state.

The convex hull of formation energies is, geometrically, the unique, minimal set containing all the formation energies. The convex hull is the phases $\operatorname{Mn}\left[\mathrm{Mn}(\mathrm{CN})_{6}\right], \operatorname{NaMn}\left[\mathrm{Mn}(\mathrm{CN})_{6}\right]$, $\mathrm{Na}_{2} \mathrm{Mn}\left[\mathrm{Mn}(\mathrm{CN})_{6}\right], \mathrm{Na}_{3} \mathrm{Mn}\left[\mathrm{Mn}(\mathrm{CN})_{6}\right]$, and sodium metal. Physically, the convex hull of formation energies defines the stable phases. For any meta-stable phase with a formation energy above the convex hull, the system's total energy will decrease on transformation into phases whose formation energies do lie on the convex hull. Since $\mathrm{Na}_{3} \mathrm{Mn}\left[\mathrm{Mn}(\mathrm{CN})_{6}\right]$ is part of the convex hull, the experimental observation of the insertion of three sodium ions into the lattice is, indeed, thermodynamically reasonable.

Figure 2 indicates that $\mathrm{Na}_{3} \mathrm{Mn}\left[\mathrm{Mn}(\mathrm{CN})_{6}\right]$ is stable against separation into $\mathrm{Na}_{2} \mathrm{Mn}\left[\mathrm{Mn}(\mathrm{CN})_{6}\right]$ and sodium metal. More generally, each of the compounds $\mathrm{Na}_{\mathrm{x}} \mathrm{Mn}\left[\mathrm{Mn}(\mathrm{CN})_{6}\right]$ (for $x \in$ $0,1,2,3)$ is stable against separation into any of the other oxidation states studied here. We note that this is one slice of the higher-dimensional set of formation energies. It is conceivable that the compound could break down into other chemical species like sodium cyanide. However, other decomposition pathways at room temperature are unlikely. First, the sample from Pasta and coworkers was cycled reversibly and stable enough to collect the XRD data discussed in the next section. Second, the low-potential behavior of a closely related composition, sodium manganese hexacyanochromate $\left(\mathrm{Na}_{\mathrm{x}} \mathrm{Mn}\left[\mathrm{Cr}(\mathrm{CN})_{6}\right]\right)$, has previously been explored experimentally. ${ }^{16}$ The lattice was found to be stable below the minimum 
potential (about $1.21 \mathrm{~V}$ versus $\mathrm{Na}^{+} / \mathrm{Na}$ ) that these calculations predict is necessary to insert the third sodium ion. Third, closely related PBA compositions have been found to be thermally stable up to $200{ }^{\circ} \mathrm{C}$ or higher. ${ }^{17}$ Interestingly, $\mathrm{Na}_{4} \mathrm{Mn}\left[\mathrm{Mn}(\mathrm{CN})_{6}\right]$ lies almost exactly on the convex hull. This indicates that insertion of a fourth sodium ion may be possible. However, it is essentially degenerate with the phase-separated mixture of sodium metal with $\mathrm{Na}_{3} \mathrm{Mn}\left[\mathrm{Mn}(\mathrm{CN})_{6}\right]$, so experimental observation would be challenging. (See Figure SI.2.)

\section{Crystal structures and sodium-ion positions}

The crystal structures and simulated X-ray diffractograms for the four oxidation states are shown in Figure 3 along with the experimental synchrotron XRD data collected by Pasta and coworkers. ${ }^{11}$ For the fully oxidized $\operatorname{Mn}\left[\mathrm{Mn}(\mathrm{CN})_{6}\right]$, the diffraction pattern for the $\mu=8 \mu_{\mathrm{B}}$ phase is shown. This phase is face-centred cubic (space group Fm $\overline{3} \mathrm{~m}$ ) with a lattice parameter of $10.7 \AA$. The most intense peak arises from the (101) reflection at $4.42^{\circ}$. It is clear that the computed cubic crystal structure for $\mu=8 \mu_{\mathrm{B}}$ is in excellent agreement with synchrotron XRD data. The $\mu=6 \mu_{\mathrm{B}}$ phase for this compound has a tetragonal crystal geometry with

lattice parameters $\mathrm{a}=10.2 \AA$ and $\mathrm{c} / \mathrm{a}=1.06$. The crystal structure and simulated XRD pattern is shown in Figure SI.3.

In the simulated pattern for the compound $\mathrm{NaMn}\left[\mathrm{Mn}(\mathrm{CN})_{6}\right]$, the most intense peaks arise from the (011) and (110) reflections at $4.42^{\circ}$ and $4.44^{\circ}$, respectively. This, too, is in excellent agreement with the synchrotron XRD data. The splitting of these peaks is indicative of the breaking of the cubic symmetry in the more oxidized phase.

The simulated pattern for $\mathrm{Na}_{2} \mathrm{Mn}\left[\mathrm{Mn}(\mathrm{CN})_{6}\right]$ is also very similar to experiment. The two peaks peaks caused by the (101) and (110) reflections are aligned with two experimental peaks centered at about $4.45^{\circ}$ and $4.47^{\circ}$. (Note that the (001) reflection at $4.27^{\circ}$ in the simulated pattern results from long range ordering of sodium ions due to the model's periodic boundary conditions. See Figure SI.4 for the pattern simulated without sodium ions.)

For $\mathrm{Na}_{3} \mathrm{Mn}\left[\mathrm{Mn}(\mathrm{CN})_{6}\right]$, the simulated data also generally match the empirical data well. 

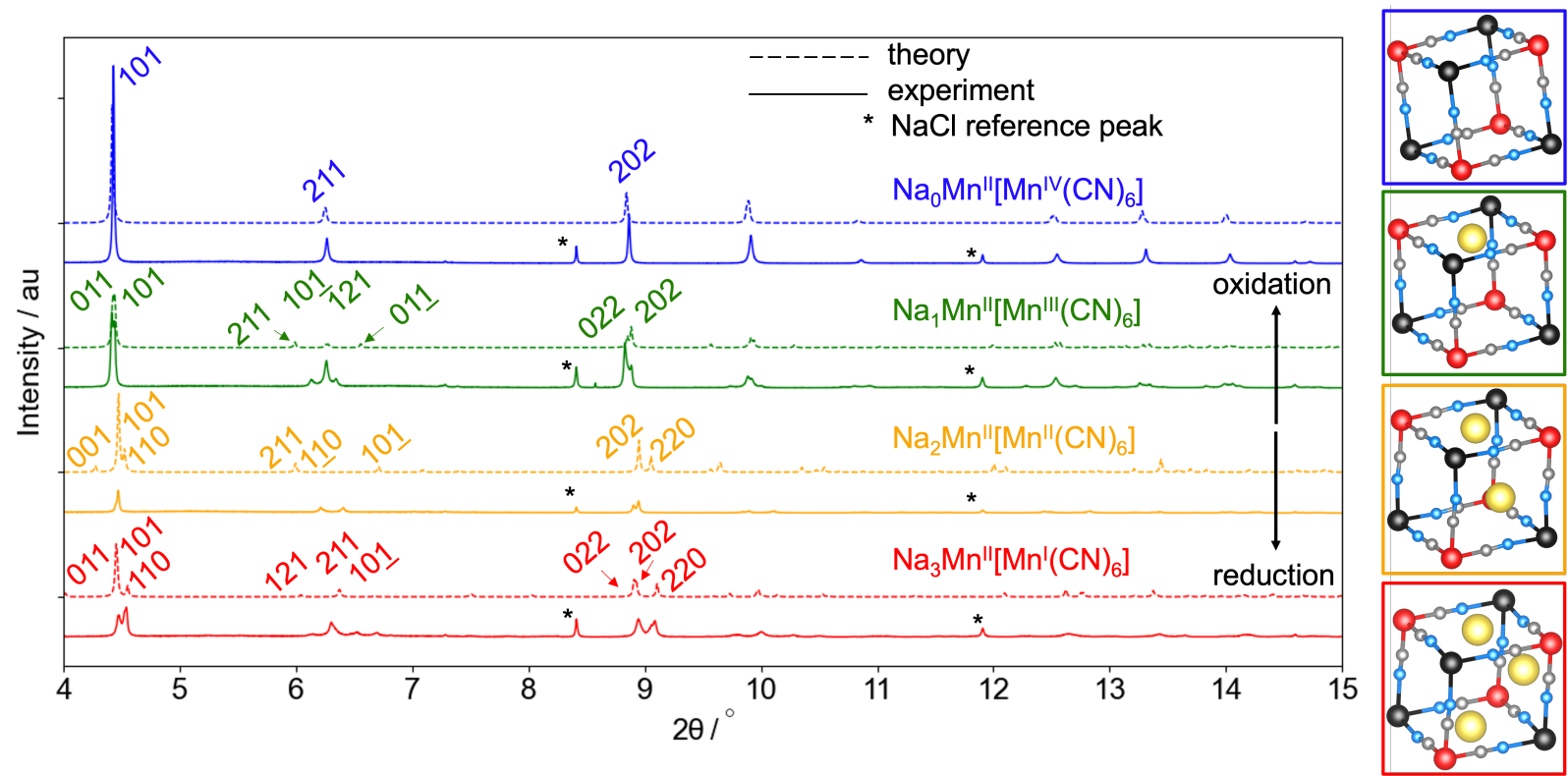

Figure 3: Crystal structures and simulated diffractograms. The simulated (dashed line) and experimental (solid line, collected by Pasta and coworkers ${ }^{11}$ ) patterns are plotted for the four compounds $\mathrm{Mn}\left[\mathrm{Mn}(\mathrm{CN})_{6}\right], \mathrm{NaMn}\left[\mathrm{Mn}(\mathrm{CN})_{6}\right], \mathrm{Na}_{2} \mathrm{Mn}\left[\mathrm{Mn}(\mathrm{CN})_{6}\right]$, and $\mathrm{Na}_{3} \mathrm{Mn}\left[\mathrm{Mn}(\mathrm{CN})_{6}\right]$. Peak indices are included for the simulated patterns and the asterisk indicates sodium chloride reference peaks in the experimental data. The corresponding crystal structures are shown at right.

The model has three reflections, (011), (101), and (110), which match three experimental peaks at $4.47^{\circ}, 4.52^{\circ}$, and $4.54^{\circ}$.

Table 1 lists the experimental lattice parameters versus the calculated values. The values are for a "cubic equivalent" cell and refer to the distance between nearest-neighbor carboncoordinated manganese ions. The values from theory are extremely close to those from experiment. The validation of the model warrants the following closer study of the electronic structure.

Table 1: Comparison of experimental and computational lattice parameters.

\begin{tabular}{cccccc}
\hline & \multicolumn{3}{c}{ Experimental } & \multicolumn{3}{c}{ Computational } \\
& $a / \AA$ & $b=c / \AA$ & $a / \AA$ & $b / \AA$ & $c / \AA$ \\
\hline $\mathrm{Mn}\left[\mathrm{Mn}(\mathrm{CN})_{6}\right]$ & \multicolumn{2}{c}{10.706} & 10.736 & 10.732 \\
$\mathrm{NaMn}\left[\mathrm{Mn}(\mathrm{CN})_{6}\right]$ & 10.688 & 10.750 & 10.728 & 10.726 \\
$\mathrm{Na}_{2} \mathrm{Mn}\left[\mathrm{Mn}(\mathrm{CN})_{6}\right]$ & 10.658 & 10.616 & 10.607 & 10.703 \\
$\mathrm{Na}_{3} \mathrm{Mn}\left[\mathrm{Mn}(\mathrm{CN})_{6}\right]$ & 10.459 & 10.905 & 10.710 & 10.633 & 10.475 \\
\hline
\end{tabular}




\section{Electronic structures and oxidation states}

The projected densities of states (PDOS) and electronic configurations that are calculated using the atom-projected magnetic moments for the four compounds are shown in Figure 4. The figure also shows the valence- and conduction-band-decomposed charge densities. All these states arise from highly localized manganese orbitals.

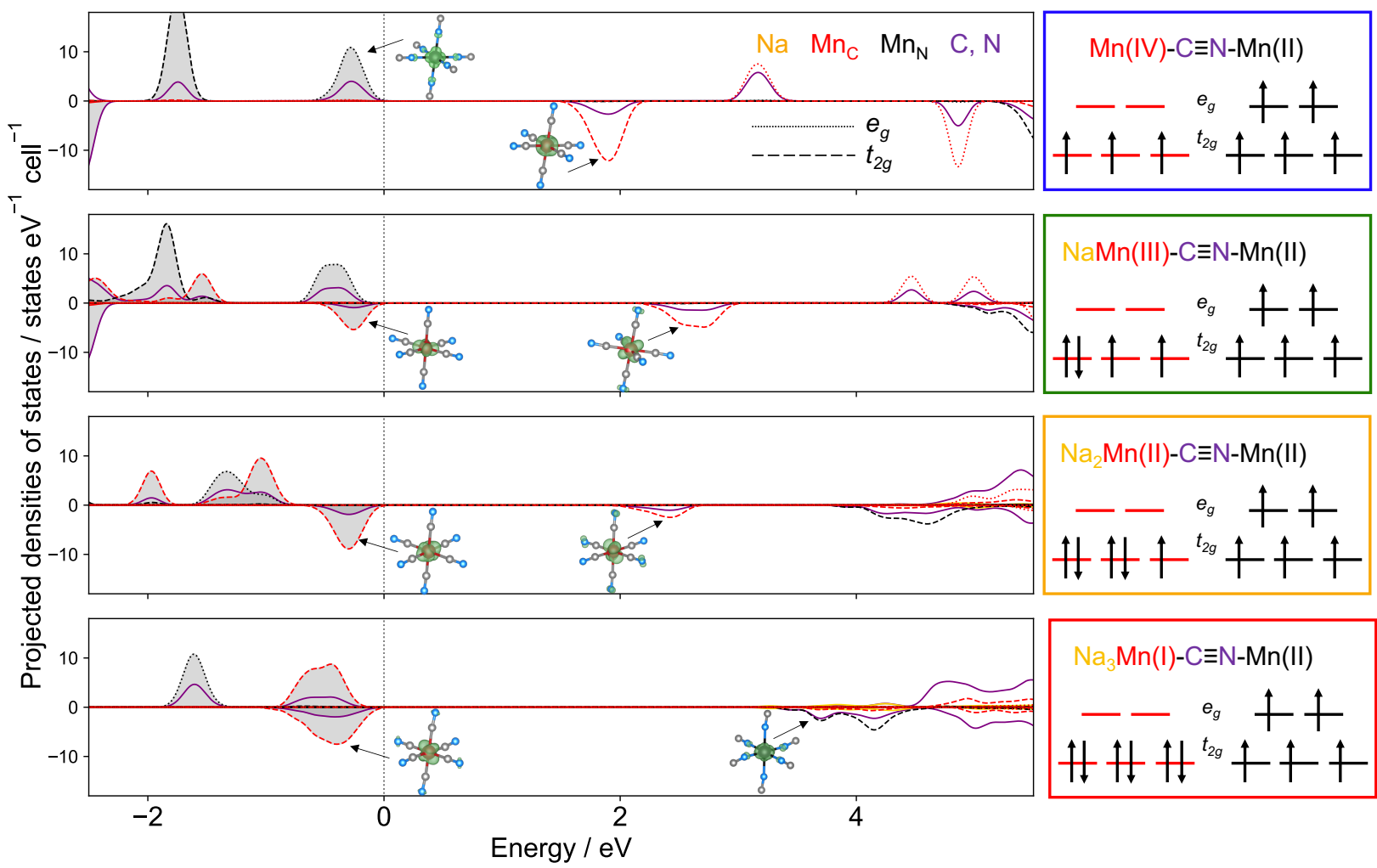

Figure 4: Projected densities of states (PDOS), band-decomposed charge densities, and electronic configurations. Plots and configurations correspond to $0,1,2$, and 3 sodium ions per formula unit from top to bottom. In the PDOS, red, black, purple, and gold lines refer to states arising from orbitals on the carbon-coordinated manganese, nitrogen-coordinated manganese, cyanide ligands, and sodium, respectively. Solid, dashed, and dotted lines refer to states arising from $(s$ and $p), t_{2 g}$, and $e_{g}$ orbitals, respectively. The charge densities shown are for the valence-band and conduction-band states.

For the fully oxidized compound, $\operatorname{Mn}\left[\mathrm{Mn}(\mathrm{CN})_{6}\right]$, the $\mu=8 \mu_{\mathrm{B}}$ phase has atom-projected magnetic moments of $\mu_{M n-C}=3.023 \mu_{B}$ and $\mu_{M n-N}=4.567 \mu_{B}$. This is consistent with an electronic configuration of $\left(\operatorname{Mn}_{\mathrm{C}}\left(t_{2 g}^{3}\right), \mathrm{Mn}_{\mathrm{N}}\left(t_{2 g}^{3} e_{g}^{2}\right)\right)$. In this phase, the nitrogen-coordinated manganese is high spin and the two manganese ions are spin-aligned. The two manganese 
ions are in oxidation states $\left(\mathrm{Mn}_{\mathrm{C}}(\mathrm{IV}), \mathrm{Mn}_{\mathrm{N}}(\mathrm{II})\right)$, so this phase is charge-disproportionated. This is an agreement with experiment. ${ }^{18}$ The PDOS shows that the conduction-band states arise from spin-down, $t_{2 g}$ orbitals on the carbon-coordinated manganese. The electronic configuration for the nearly degenerate $\mu=6 \mu_{\mathrm{B}}$ is $\left(\mathrm{Mn}_{\mathrm{C}}\left(t_{2 g}^{4}\right), \mathrm{Mn}_{\mathrm{N}}\left(t_{2 g}^{3} e_{g}^{1}\right)\right)$. This oxidation state, $\left(\mathrm{Mn}_{\mathrm{C}}(\mathrm{III}), \mathrm{Mn}_{\mathrm{N}}(\mathrm{III})\right)$, has a singly occupied $e_{g}$ orbital which gives rise to a Jahn-Teller distortion and the tetragonal geometry discussed above.

On reduction to the compound $\mathrm{NaMn}\left[\mathrm{Mn}(\mathrm{CN})_{6}\right]$, the spin-down, carbon-coordinated $t_{2 g}$ orbitals become partially occupied; both the valence- and conduction-bands arise from spindown, $t_{2 g}$ orbitals on the carbon-coordinated manganese. The atom-projected magnetic moments for this $\mu=7 \mu_{\mathrm{B}}$ phase are $\mu_{M n-C}=2.013 \mu_{B}$ and $\mu_{M n-N}=4.572 \mu_{B}$; the orbital occupations are $\left(\operatorname{Mn}_{\mathrm{C}}\left(t_{2 g}^{4}\right), \mathrm{Mn}_{\mathrm{N}}\left(t_{2 g}^{3} e_{g}^{2}\right)\right)$. In this phase, the nitrogen-coordinated carbon remains high spin and the two manganese ions are spin-aligned.

Further reduction to the compound $\mathrm{Na}_{2} \mathrm{Mn}\left[\mathrm{Mn}(\mathrm{CN})_{6}\right]$ adds an electron to the spin-down, carbon-coordinated-manganese $t_{2 g}$ orbital, resulting in increased density of states in the valence band arising from these orbitals. The conduction band still originates from these same, carbon-coordinated-manganese, spin-down $t_{2 g}$ orbitals (albeit with lower density of states). The atom-projected magnetic moments are $\mu_{M n-C}=1.075 \mu_{B}$ and $\mu_{M n-N}=4.567 \mu_{B}$ and the electronic configuration is $\left(\operatorname{Mn}_{\mathrm{C}}\left(t_{2 g}^{5}\right), \mathrm{Mn}_{\mathrm{N}}\left(t_{2 g}^{3} e_{g}^{2}\right)\right)$. The nitrogen-coordinated manganese is still high spin and the manganese ions are still spin-aligned.

Reduction to the $\mathrm{Na}_{3} \mathrm{Mn}\left[\mathrm{Mn}(\mathrm{CN})_{6}\right]$ fully occupies the $t_{2 g}$ orbitals on the carbon-coordinated manganese, so the valence band arises from these orbitals. The atom-projected magnetic moments are $\mu_{M n-C}=0.094 \mu_{B}$ and $\mu_{M n-N}=4.561 \mu_{B}$. This implies an orbital occupation of $\left(\operatorname{Mn}_{\mathrm{C}}\left(t_{2 g}^{6}\right), \mathrm{Mn}_{\mathrm{N}}\left(t_{2 g}^{3} e_{g}^{2}\right)\right)$ with high-spin nitrogen-coordinated manganese.

The theoretical compound $\mathrm{Na}_{4} \mathrm{Mn}\left[\mathrm{Mn}(\mathrm{CN})_{6}\right]$ would be naively expected to attain an oxidation state of either $\left(\mathrm{Mn}_{\mathrm{C}}(\mathrm{I}), \mathrm{Mn}_{\mathrm{N}}(\mathrm{I})\right)$ or perhaps even $\left(\mathrm{Mn}_{\mathrm{C}}(0), \mathrm{Mn}_{\mathrm{N}}(\mathrm{II})\right)$. However, the atom-projected magnetic moments on the two manganese ions are equal to those in the $\mathrm{Na}_{3} \mathrm{Mn}^{\mathrm{II}}\left[\mathrm{Mn}^{\mathrm{I}}(\mathrm{CN})_{6}\right]$ system. And, as Figure SI.5 shows, the valence band states arise from 
sodium orbitals. The only difference between the degenerate $4 \mu_{B}$ and $6 \mu_{B}$ phases is the spin of the electron on the sodium atom; the electronic structures of the lattice ions are identical in the two magnetic phases.

Overall, the high specific capacity in sodium manganese hexacyanomanganate originates, in part, from the fact that $\mathrm{Na}_{2} \mathrm{Mn}\left[\mathrm{Mn}(\mathrm{CN})_{6}\right]$ has a relatively low-energy conduction-band state arising from an unoccupied $t_{2 g}$ orbital on the carbon-coordinated manganese. Reduction to $\mathrm{Na}_{3} \mathrm{Mn}\left[\mathrm{Mn}(\mathrm{CN})_{6}\right]$ results in the particularly stable electronic configuration $\left(\mathrm{Mn}_{\mathrm{C}}\left(t_{2 g}^{6}\right)\right.$, $\left.\operatorname{Mn}_{\mathrm{N}}\left(t_{2 g}^{3} e_{g}^{2}\right)\right)$. The nitrogen-coordinated manganese ion remains manganese(II) over the course of three reduction events from $\mathrm{Mn}\left[\mathrm{Mn}(\mathrm{CN})_{6}\right]$ to $\mathrm{Na}_{3} \mathrm{Mn}\left[\mathrm{Mn}(\mathrm{CN})_{6}\right]$. The carboncoordinated manganese is the exclusive redox center in this system, changing oxidation state from +4 to +3 to +2 to +1 . Furthermore, the nitrogen-coordinated manganese is always high spin, and the two manganese ions are always ferromagnetically aligned. (Though in $\mathrm{Na}_{3} \mathrm{Mn}^{\mathrm{II}}\left[\mathrm{Mn}^{\mathrm{I}}(\mathrm{CN})_{6}\right]$, the carbon-coordinated manganese ion's magnetic moment is 0 .)

\section{Effect of crystalline water}

The grand potential governs the phase stability of the compositions $\mathrm{Na}_{\mathrm{x}} \mathrm{Mn}\left[\mathrm{Mn}(\mathrm{CN})_{6}\right] \cdot \mathrm{wH}_{2} \mathrm{O}$ for various values of $x$ and $w$. Following the method of Ong and coworkers, ${ }^{19}$ the grand potential is given by:

$$
\Phi=G\left(\mathrm{Na}_{\mathrm{x}} \mathrm{Mn}\left[\mathrm{Mn}(\mathrm{CN})_{6}\right] \cdot \mathrm{wH}_{2} \mathrm{O}\right)-x \mu_{N a}-w \mu_{\mathrm{H}_{2} O}
$$

in which $G\left(\mathrm{Na}_{\mathrm{x}} \mathrm{Mn}\left[\mathrm{Mn}(\mathrm{CN})_{6}\right]\right)$ is the Gibbs energy (approximated by the DFT free energy), $\mu_{N a}$ is the chemical potential of the sodium particles, and $\mu_{\mathrm{H}_{2} \mathrm{O}}$ is the chemical potential of the water particles. The chemical potential of water, $\mu_{H_{2} O}$, can be expressed as:

$$
\mu_{\mathrm{H}_{2} \mathrm{O}}=\mu_{\mathrm{H}_{2} \mathrm{O}}^{0}+k_{B} T \ln \left(a_{\mathrm{H}_{2} \mathrm{O}}\right)
$$

in which $\mu_{\mathrm{H}_{2} \mathrm{O}}^{0}$ is the reference chemical potential for water and $a_{\mathrm{H}_{2} \mathrm{O}}$ is the activity of water 
in a liquid electrolyte. The sodium chemical potential is related to the electric potential (or voltage), $V$, by:

$$
V=-\frac{\mu_{N a}-\mu_{N a}^{0}}{e}
$$

where $\mu_{N a}^{0}$ is the reference chemical potential of sodium metal and $e$ is the fundamental charge.

To calculate the energies of the monohydrate and dihydrate phases, water molecules were explicitly included in the crystal structure and full relaxation of the lattice vectors and atoms positions was performed using the HSE functional. The phase diagram that results for the $\mathrm{Na}_{\mathrm{x}} \mathrm{Mn}\left[\mathrm{Mn}(\mathrm{CN})_{6}\right] \cdot \mathrm{wH}_{2} \mathrm{O}$ system is shown in Figure 5a. At the lowest chemical potential for water (that is, for the driest electrolyte), the dehydrated $(w=0)$ phase is most stable for all four oxidation states $(x=0$ to $x=3$ ). At the highest chemical potential for water (that is, the wettest electrolyte) the most stable phase has two water molecules per formula unit for $x=1,2,3$. For the $x=0$ compound, though, the dehydrated compound remains the most stable, and neither $\mathrm{Mn}\left[\mathrm{Mn}(\mathrm{CN})_{6}\right] \cdot \mathrm{H}_{2} \mathrm{O}$ nor $\mathrm{Mn}\left[\mathrm{Mn}(\mathrm{CN})_{6}\right] \cdot 2 \mathrm{H}_{2} \mathrm{O}$ appears in the phase diagram. The intermediate hydration states, $\mathrm{NaMn}\left[\mathrm{Mn}(\mathrm{CN})_{6}\right] \cdot \mathrm{H}_{2} \mathrm{O}, \mathrm{Na}_{2} \mathrm{Mn}\left[\mathrm{Mn}(\mathrm{CN})_{6}\right] \cdot \mathrm{H}_{2} \mathrm{O}$, and $\mathrm{Na}_{3} \mathrm{Mn}\left[\mathrm{Mn}(\mathrm{CN})_{6}\right] \cdot \mathrm{H}_{2} \mathrm{O}$, are the ground state at intermediate water chemical potentials.

Water has the effect of increasing the reduction potential in closely related PBA compositions, ${ }^{19}$ and it also increases the reduction potential of this $\mathrm{Na}_{\mathrm{x}} \mathrm{Mn}\left[\mathrm{Mn}(\mathrm{CN})_{6}\right] \cdot \mathrm{wH}_{2} \mathrm{O}$ system as shown in Figure 5b. The calculated reduction potential for the $\mathrm{Mn}^{\mathrm{II}}\left[\mathrm{Mn}^{\mathrm{III} / \mathrm{IV}}(\mathrm{CN})_{6}\right]$ couple is $3.17 \mathrm{~V}$ versus $\mathrm{Na}^{+} / \mathrm{Na}$; this underestimates the observed average potential of about $3.5 \mathrm{~V}$ by $330 \mathrm{mV}$. The $\mathrm{Mn}^{\mathrm{II}}\left[\mathrm{Mn}^{\mathrm{II} / \mathrm{III}}(\mathrm{CN})_{6}\right]$ has a calculated reduction potential of $2.12 \mathrm{~V}$ versus $\mathrm{Na}^{+} / \mathrm{Na}$, which is $580 \mathrm{mV}$ below the observed average value of about $2.7 \mathrm{~V}$. Finally, the $\mathrm{Mn}^{\mathrm{II}}\left[\mathrm{Mn}^{\mathrm{I} / \mathrm{II}}(\mathrm{CN})_{6}\right]$ couple is computationally at $1.21 \mathrm{~V}$ versus $\mathrm{Na}^{+} / \mathrm{Na}$, while the average experimental data is around $1.8 \mathrm{~V}$, or $590 \mathrm{mV}$ higher. However, the reduction potentials for the hydrated materials at higher chemical potential are 3.4, 2.7, and $1.7 \mathrm{~V}$ versus $\mathrm{Na}^{+} / \mathrm{Na}$. These are in much better agreement with experiment, underestimating observed values by 100, 0, and $100 \mathrm{mV}$. Figure SI.6 shows that the crystal structures of the hydrated compounds 

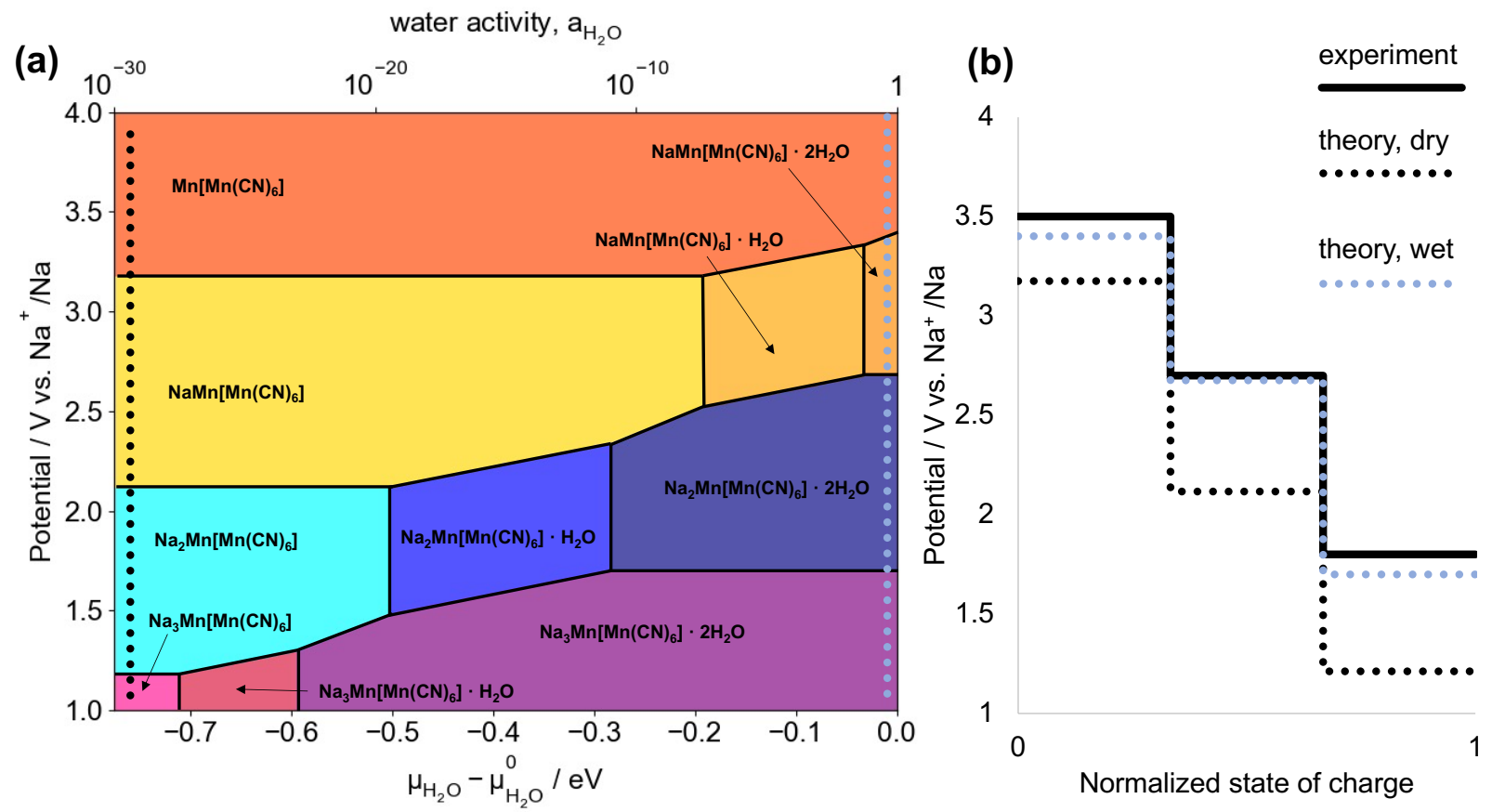

Figure 5: Phase diagram and simulated galvanostatic curve. In (a), the stable phase of the $\mathrm{Na}_{\mathrm{x}} \mathrm{Mn}\left[\mathrm{Mn}(\mathrm{CN})_{6}\right] \cdot \mathrm{wH}_{2} \mathrm{O}$ system is plotted as a function of voltage and chemical potential of water at $300 \mathrm{~K}$. In (b), the simulated galvanostatic discharge curves are plotted for a drier electrolyte (lower chemical potential for water) (black dotted line) and for a wetter electrolyte (higher chemical potential for water) (blue dotted line). The average experimental potential is plotted from Pasta and coworkers ${ }^{11}$ for comparison. 
agree with experiment as well as or better than the structures in Figure 3.

\section{Conclusions}

DFT calculations with a hybrid functional reveal that the high specific capacity in sodium manganese hexacyanomanganate arises from the insertion of a third sodium ion into the formula unit, forming $\mathrm{Na}_{3} \mathrm{Mn}^{\mathrm{I}}\left[\mathrm{Mn}^{\mathrm{II}}(\mathrm{CN})_{6}\right]$. All three sodium ions occupy different faces of the interstitial subcube. This compound lies on the convex full of formation energies for this system on account of the particularly stable electronic configuration $\left(\operatorname{Mn}_{\mathrm{C}}\left(t_{2 g}^{6}\right), \mathrm{Mn}_{\mathrm{N}}\left(t_{2 g}^{3} e_{g}^{2}\right)\right)$. This compound includes the somewhat rare manganese(I) species. The hydrated form of the compound, $\mathrm{Na}_{3} \mathrm{Mn}^{\mathrm{I}}\left[\mathrm{Mn}^{\mathrm{II}}(\mathrm{CN})_{6}\right] \cdot 2 \mathrm{H}_{2} \mathrm{O}$ is also stable at high chemical potential for liquid water. Hydration of this materials increases the reduction potential versus $\mathrm{Na}^{+} / \mathrm{Na}$. One question that remains is why the experimentally observed specific capacity, $209 \mathrm{~mA} \mathrm{~h} \mathrm{~g}^{-1}$, is lower than the theoretical value for the as-synthesized $229 \mathrm{~mA} \mathrm{~h} \mathrm{~g}^{-1}$, a difference of $9 \%$. The physico-chemical characterization of the as-synthesized material and the good agreement between theory and experiment seem to exclude the presence of hexacyanometallate vacancies as a justification for this discrepancy. A more plausible explanation is that the specific capacity is limited by the electrode's kinetics. Komaba and coworkers reported the beneficial effect of vacancies on K-ion conduction in potassium manganese hexacyanoferrate, highlighting the limited diffusivity in the vacancy-free material. ${ }^{20}$ Future theoretical work can examine the activation energy for ion movement through the lattice using, for instance, nudged-elastic-band method. This work provides a convincing explanation for the origin of the highest-ever observed reversible specific capacity in a PBA and is an important contribution to the theory of PBA electrodes. 


\section{Methods}

We performed all DFT calculations using the Vienna ab inito Simulation Package (VASP). ${ }^{21,22}$ We used a $\Gamma$-centered 4x4x4 k-point grid and a plane-wave kinetic-energy cutoff of $520 \mathrm{eV}$. The convergence criteria were $10^{-5} \mathrm{eV}$ and $0.05 \mathrm{eV} \AA^{-1}$, respectively. Full geometric relaxation was performed on all materials first within the generalized-gradient-approximation using the Perdew-Burke-Ernzerhof (PBE) functional ${ }^{23}$ and then with the non-local, hybrid

Heyd-Scuseria-Ernzerhof (HSE) functional. ${ }^{24}$ For the HSE functional, we used a screening parameter of $0.2 \AA^{-1}$ and a mixing of $25 \%$ Fock exchange with $75 \%$ PBE exchange. For the structures that contain water, water molecules were included explicitly in the model and full relaxation of the lattice vectors and atom positions (including water) were performed again using the HSE functional. Water molecules were places in the subcubes with the sodium ions; the lower-energy configuration is the migration of the sodium ions to the cubcube faces and the migration of the water molecules to the centers of the subcubes. In calculating the formation energies, the reference energy for $\operatorname{Mn}\left[\mathrm{Mn}(\mathrm{CN})_{6}\right]$ was the energy of the $6 \mu_{B}$ phase. The X-ray diffraction reflections were calculated using an incident photon wavelength of $\lambda=0.413737 \AA$ in VESTA and the diffractograms were simulated using a Lorentzian function with $\gamma=0.01^{\circ}$.

\section{Acknowledgement}

We gratefully acknowledge the use of the following computer resources: the University of Oxford Advanced Research Computing (ARC) facility (http://dx.doi.org/10.5281/zenodo.22558); and PRACE for awarding time on Beskow based in Sweden at KTH and on ARCHER in the United Kingdom (http://www.archer.ac.uk) through projects 16DECI0064 and 17DECI0090. $\mathrm{KH}$ and MP would like to acknowledge the financial support of the ISCF Faraday Challenge project SOLBAT grant number FIRG026. 


\section{Supporting Information Available}

Supporting information is available online.

\section{References}

(1) Qian, J.; Wu, C.; Cao, Y.; Ma, Z.-F.; Huang, Y.; Ai, X.; Yang, H. Prussian Blue Cathode Materials for Sodium-Ion Batteries and Other Ion Batteries. Advanced Energy Materials 2018, 1702619, 1-24.

(2) Wang, L.; Lu, Y.; Liu, J.; Xu, M.; Cheng, J.; Zhang, D.; Goodenough, J. B. A Superior Low-Cost Cathode for a Na-Ion Battery. Angewandte 2013, 1964-1967.

(3) Song, J.; Wang, L.; Lu, Y.; Liu, J.; Guo, B.; Xiao, P.; Lee, J. J.; Yang, X. Q.; Henkelman, G.; Goodenough, J. B. Removal of interstitial H2O in hexacyanometallates for a superior cathode of a sodium-ion battery. Journal of the American Chemical Society 2015, 137, 2658-2664.

(4) Fiore, M.; Wheeler, S.; Hurlbutt, K.; Capone, I.; Fawdon, J.; Ruffo, R.; Pasta, M. Paving the Way Toward Highly Efficient High-Energy Potassium-Ion Batteries with Ionic-Liquid Electrolytes. Chemistry of Materials 2020, 32, 7653-7661.

(5) Lee, H.-w.; Pasta, M.; Wang, R. Y. Effect of the alkali insertion ion on the electrochemical properties of nickel hexacyanoferrate electrodes. Faraday Discussions 2014, 176, 69-81.

(6) Wang, R. Y.; Wessells, C. D.; Huggins, R. A.; Cui, Y. Highly reversible open framework nanoscale electrodes for divalent ion batteries. Nano Letters 2013, 13, 5748-5752.

(7) Reed, L. D.; Ortiz, S. N.; Xiong, M.; Menke, E. J. A rechargeable aluminum-ion battery utilizing a copper hexacyanoferrate cathode in an organic electrolyte. Chem. Commun. 2015, 51, 14397-14400. 
(8) Hurlbutt, K.; Wheeler, S.; Capone, I.; Pasta, M. Prussian Blue Analogs as Battery Materials. Joule 2018, 2, 1950-1960.

(9) Cammarata, M.; Zerdane, S.; Balducci, L.; Azzolina, G.; Mazerat, S.; Exertier, C.; Trabuco, M.; Levantino, M.; Alonso-Mori, R.; Glownia, J. M.; Song, S.; Catala, L.; Mallah, T.; Matar, S. F.; Collet, E. Charge transfer driven by ultrafast spin transition in a CoFe Prussian blue analogue. Nature Chemistry 2021, 13, 10-14.

(10) Wojdel, J. C.; De P. R. Moreira, I.; Bromley, S. T.; Illas, F. On the prediction of the crystal and electronic structure of mixed-valence materials by periodic density functional calculations: The case of Prussian Blue. Journal of Chemical Physics 2008, 128.

(11) Lee, H.-W.; Wang, R. Y.; Pasta, M.; Woo Lee, S.; Liu, N.; Cui, Y. Manganese hexacyanomanganate open framework as a high-capacity positive electrode material for sodium-ion batteries. Nature communications 2014, 5, 5280.

(12) Firouzi, A.; Qiao, R.; Motallebi, S.; Valencia, C. W.; Israel, H. S.; Fujimoto, M.; Wray, L. A.; Chuang, Y.-D.; Yang, W.; Wessells, C. D. Monovalent manganese based anodes and co-solvent electrolyte for stable low-cost high-rate sodium-ion batteries. Nature Communications 2018, 9, 861.

(13) Hurlbutt, K.; Giustino, F.; Pasta, M.; Volonakis, G. Electronic Structure and ElectronTransport Properties of Three Metal Hexacyanoferrates. Chemistry of Materials 2021,

(14) Xiao, P.; Song, J.; Wang, L.; Goodenough, J. B.; Henkelman, G. Theoretical study

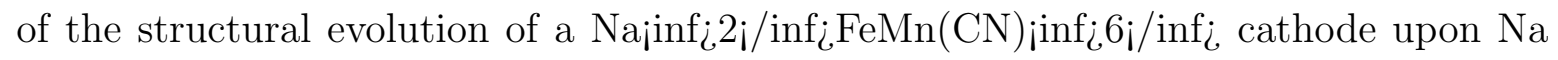
intercalation. Chemistry of Materials 2015, 27, 3763-3768.

(15) Mayo, M.; Griffith, K. J.; Pickard, C. J.; Morris, A. J. Ab Initio Study of Phosphorus Anodes for Lithium- and Sodium-Ion Batteries. Chemistry of Materials 2016, 28, 20112021. 
(16) Wheeler, S.; Capone, I.; Day, S.; Tang, C.; Pasta, M. Low Potential Prussian Blue Analogs : Manganese Hexacyanochromate. Chemistry of Materials 2019,

(17) Parajuli, D.; Tanaka, H.; Sakurai, K.; Hakuta, Y.; Kawamoto, T. Thermal decomposition behavior of prussian blue in various conditions. Materials 2021, 14, 1-17.

(18) Klenze, R.; Kanellakopulos, B.; Trageser, G.; Eysel, H. H. Manganese hexacyanomanganate: Magnetic interactions via cyanide in a mixed valence Prussian blue type compound. The Journal of Chemical Physics 1980, 72, 5819-5828.

(19) Guo, X.; Wang, Z.; Deng, Z.; Li, X.; Wang, B.; Chen, X.; Ong, S. P. Water Contributes to Higher Energy Density and Cycling Stability of Prussian Blue Analogue Cathodes for Aqueous Sodium-Ion Batteries. Chemistry of Materials 2019, acs.chemmater.9b02269.

(20) Hosaka, T.; Fukabori, T.; Kojima, H.; Kubota, K.; Komaba, S. Effect of Particle Size and Anion Vacancy on Electrochemical Potassium Ion Insertion into Potassium Manganese Hexacyanoferrates. ChemSusChem 2021, 14, 1166-1175.

(21) Kresse, G.; Furthmüller, J.; Hafner, J. Theory of the crystal structures of selenium and tellurium: The effect of generalized-gradient corrections to the local-density approximation. Phys. Rev. B 1994, 50, 13181-13185.

(22) Kresse, G.; Furthmüller, J. Efficiency of ab-initio total energy calculations for metals and semiconductors using a plane-wave basis set. Comp. Mater. Sci. 1996, 6, 15-50.

(23) Perdew, J. P.; Burke, K.; Ernzerhof, M. Generalized Gradient Approximation Made Simple. Phys. Rev. Lett. 1996, 77, 3865-3868.

(24) Heyd, J.; Scuseria, G. E.; Ernzerhof, M. Hybrid functionals based on a screened Coulomb potential. J. Chem. Phys. 2003, 118, 8207-8215. 